\title{
Predicator of Pregnant Women's Self-care Behavior against Air Pollution: An explanation based on the Extended Parallel Process Model (EPPM)
}

\author{
Mehrnoosh Jasemzadeh $^{1}$, Nematallah Jaafarzadeh ${ }^{2}$, Morteza Abdullatif Khafaie ${ }^{3}$, Amal Saki Malehi ${ }^{4}$, Marzieh \\ Araban $^{5}$
}

${ }^{1}$ M.Sc. Student in Health Education, Department of Public Health, Social Determinants of Health Research center, Faculty of Health, Ahvaz Jundishapur University of Medical Sciences, Ahvaz, Iran

${ }^{2} \mathrm{Ph} . D$. of Environmental Health Engineering, Professor, Environmental Technologies Research Center, Faculty of Health, Ahvaz Jundishapur University of Medical Sciences, Ahvaz, Iran

${ }^{3}$ MPH, Ph.D. in Health Science, Assistant Professor, Social Determinants of Health Research center, Faculty of Health, Ahvaz Jundishapur University of Medical Sciences, Ahvaz, Iran

${ }^{4}$ Ph.D. of Biostatistics, Assistant Professor, Department of Biostatistics and Epidemiology, Faculty of Health, Ahvaz Jundishapur University of Medical Sciences, Ahvaz, Iran

${ }^{5}$ Ph.D. of Health Education, Assistant Professor, Social Determinants of Health Research Center, Health Education and Health Promotion Department, Faculty of Health, Ahvaz Jundishapur University of Medical Sciences, Ahvaz, Iran

\section{Type of article: Original}

\begin{abstract}
Introduction: Air pollution is one of the most important problems of metropolitan cities. The level of air pollution in the city of Ahvaz is so much higher than the standard level, that it can create risks, particularly for pregnant women in the area. The aim of the study was to examine the predictors of self-care behavior of pregnant women against air pollution according to Extended Parallel Process Model (EPPM) in Ahvaz.

Methods: In this cross-sectional study, 330 pregnant women who were referred to health care centers in western Ahvaz in 2015 were examined. The data collection tool was a reliable and valid researcher-made questionnaire consisting of three parts: The first part was demographic information, the second part according to the extended parallel process model, included perceived susceptibility, perceived severity, response efficacy, and self-efficacy. The third part examined self-care behavior. Then, the collected data was analyzed by using the software SPSS 16. Data analysis was done by using Spearman's correlation coefficient and linear regression.

Results: The average age of study subjects was $26.07 \pm 2.3$ years, and most $(45.5 \%)$ were in the second trimester of pregnancy. These findings showed that self-efficacy constructs $(\beta=0.41)$ and response efficacy $(\beta=0.15)$ have predictive power of self-care behavior $(\mathrm{p}<0.05)$.

Conclusion: The findings showed that self-efficacy and response efficacy, are important factors to predict air pollution self-care behavior. Therefore, to develop a theory-based behavioral modification program for pregnant women, more emphasis on these constructs is recommended.
\end{abstract}

Keywords: Air pollution, Pregnancy, Extended parallel process model, Self-care behavior, Ahvaz

\section{Introduction}

Air pollution is one of the most important problems of metropolitan cities. Caused by emissions of particulate matter, chemical, and biological materials, air pollution seriously threatens the health status of the residents of these regions and causes a variety of acute and chronic diseases $(1,2)$. The amount of air pollution in some cities of regions such as China, Italy, Canada, and Japan has been reported beyond the threshold of permissible limit (3-6).

\section{Corresponding author:}

Assistant Professor Dr. Marzieh Araban, Social Determinants of Health Research Center, Health Education and Health Promotion Department, Faculty of Health, Ahvaz Jundishapur University of Medical Sciences, Ahvaz, Iran. Tel: +98.6133738315-2872, Fax:+98.6133738315, Email: arabanm@ajums.ac.ir and araban62@gmail.com Received: March 28, 2016, Accepted: May 15, 2016, Published: September 2016 iThenticate screening: May 15, 2016, English editing: July 24, 2016, Quality control: August 01, 2016

(C) 2016 The Authors. This is an open access article under the terms of the Creative Commons Attribution-NonCommercialNoDerivs License, which permits use and distribution in any medium, provided the original work is properly cited, the use is non-commercial and no modifications or adaptations are made. 
Due to several reasons including: geographic location, proximity to Saudi Arabia, Iraq, and Kuwait, the presence of heavy industries such as steel, pipe mills, and oil refineries, in addition to pollution caused by everyday traffic congestion, makes this problem more critical in Ahvaz.. The widespread presence of dust raises concerns about the threat to citizens' health in Ahvaz $(7,8)$. Documents showed that the amount of dust pollution in Ahvaz has been more intense since 2001 (9). This important factor causes great disruption in various aspects of ordinary people's lives and environmental problems in a way that in the most severe cases, dust causes the closure of industrial and training facilities and thousands of people being referred to hospitals as a result of recurrent cardiovascular and respiratory diseases (7). Air pollution is a serious threat to the health of pregnant mothers, and studies have shown the relationship between increased concentrations of carbon monoxide in environment and miscarried pregnancies. $(1,10)$. Studies also suggest a relationship between air pollution and pregnancy outcome such as low birth weight and gestational age. These outcomes subsequently are associated with cognitive function and also the prevalence of neurologic disorders in children $(11,12)$. Therefore, pregnant women and their infants, due to physiological changes that occur during pregnancy, are among the most sensitive groups to air pollution. For these reasons, researchers believe that exposure to air pollution during pregnancy should be avoided (13). Considering that a change in behavior is the basis for the prevention of health related risks, it is recommended as a strategy to reduce exposure to air pollution and reduce its complications (14-16). Pregnancy is an ideal time for behavioral intervention, because the health risks for the fetus motivates pregnant women to change behavior and therefore a good opportunity to provide education and health interventions (17). One of the important activities recommended today to maintain and improve health is self-care debate. Self-care is the first step of healthy living. Self-care is defined as each one using his or her knowledge and skill as a resource to "independently" care for his or her health. Health professionals believe that efficiency of behavioral changes and promoting self-care behavior are firmly related to applying the theories of health education (18). Additionally, choosing an appropriate model of training programs is the first step in health education and promotion of self-care behavior (13). EPPM has been proposed as one of the models in designing health messages which is categorized as a model based on confrontation and fear. Fear appeal messages are among the persuasive messages that warn people if they do not follow the recommendations contained in the message, accidents and consequences will happen to them. The model was presented by Kim Witte in 1992 and explains how individuals respond to fear appeal messages. This model consists of four theoretical variables that are perceived susceptibility, perceived severity, response efficacy, and self-efficacy. The susceptibility variable shows one's perception of susceptibility to illness or a special event. Perceived severity is one's perception of severity and seriousness of a related disease or event. Response efficacy is the belief that a response can effectively prevent the threat. Efficacy means one's perceived understanding of ability to perform a behavior successfully (19), with regard to the fact that one way to reduce diseases caused by air pollution is carrying out self-care behavior (protective behavior). In addition, EPPM is in fact a widely used theoretical model to design fear appeal messages that encourage the audience to perform behavior that reduces the risks (threats) (20). Therefore, this study examining the predictors of self-care behavior of pregnant women against air pollution based on EPPM was conducted in Ahvaz.

\section{Material and Methods}

\subsection{Research Design and Sampling}

In this cross-sectional study, 330 pregnant women who were referred to health care centers of Health Center of west of Ahvaz in 2015 were examined. 330 pregnant women were selected. The sample size was calculated based on the thumbnails theory "10 units per question" (21). Sampling was carried out initially at health centers of West Health Center of Ahvaz; subsequently, samples of eligible people in each center were randomly selected in proportion to the number of referred people.

\subsection{Inclusion Criteria}

Inclusion criteria consisted of living in Ahvaz, being literate, having no history of health problems and consent to participate in the study.

\subsection{Measurement Tool}

In this study, a questionnaire was used to collect information consisting of three parts. The first part was a demographic questionnaire that included variables of the mother's age, gestational age, pregnancy trimester, the woman's employment and education history, and the employment and education history of their husbands. The second part of the questionnaire was designed based on model structures which have variables of perceived susceptibility including four questions (with a score range between 4 to 20) examining one's perception of susceptibility to disease and the effects of air pollution; perceived severity including six questions (with a score range between 6 to 30) examining one's perception of severity of the diseases and complications due to air 
pollution; response efficacy including five questions (with a score range between 5 to 25) examining one's belief that favorable responses to the air pollution can effectively prevent health threats caused by air pollution; selfefficacy including ten questions (with a score range between 10 to 50) examining one's perceived perception of ability to perform self-care behavior against air pollution. The third part of the questionnaire examined self-care behavior including sixteen questions (with a score range between 16 and 80). The self-care questionnaire contained questions on reducing exposure to indoor and outdoor air pollution as well as nutritional modification during air pollution crisis.

\subsection{Validity and reliability}

Validity of the questionnaire was examined by asking the views of 10 experts in the field of health education, midwifery, and environmental health. In the qualitative content validity, experts' views were taken by using a difficulty level, an ambiguity level, and by observing the Persian language grammar, using the correct vocabulary, and proper item allocation. In the quantitative content validity, experts' views on the aspects of simplicity, relevance, and clarity of each of the items and also the necessity of each item were examined, based on the Waltz criteria (22). After applying their views in the questionnaire and amending some errors, its validity was confirmed $(\mathrm{CVI}=0.89$ and $\mathrm{CVR}=1)$. To determine reliability, the questionnaires were given to 20 pregnant women similar to the target group, to calculate the internal consistency. Based on that, the amount of Cronbach's alpha coefficient of model structures was obtained as follows: (perceived susceptibility: 0.65 , perceived severity: 0.85 , response efficacy: 0.92 and self-efficacy: 0.94 ).

\subsection{Data Collection}

To collect data, first, addresses and names of all health centers of the West Health Center of Ahvaz were extracted. Then four centers were selected randomly. In this study, only urban centers were considered. Using a simple randomization method, the subjects were selected among eligible individuals of each center. Then, to evaluate the predictors of self-care behavior against air pollution, the questionnaires were given to subjects. The mean time to filling out a questionnaire was 12 minutes.

\subsection{Statistical Analysis}

Variables of perceived susceptibility, perceived severity, response efficacy, and self-efficacy as independent variables and self-care behavior as the dependent variable were entered into the regression model. Data were analyzed by SPSS16 using descriptive statistics and Spearman's correlation coefficient and linear regression.

\subsection{Research ethics}

This study was approved by the ethics committee of Ahvaz Jundishapur University of Medical Sciences (AJUMS) (letter number 1557.d.20.8.p on 06.01.2015). Before the study commenced, the aim of the study was explained to the participants. To take ethical considerations the following actions were carried out: First, informed consent was obtained from the participants. In addition, voluntarily participation and confidentiality were stressed. The used questionnaire was distributed anonymously.

\section{Results}

In this study, 330 pregnant women referred to urban health care centers in West Health Center of Ahvaz who met the inclusion criteria were examined. The mean age of these patients was $26.07+2.3$ years. 87 participants $(26.3 \%)$ were in the first trimester of pregnancy, $150(45.5 \%)$ in the second trimester of pregnancy and $93(28.2 \%)$ in the third trimester of pregnancy. The pregnancy order of individuals was as follows: 128 participants $(40 \%)$ in the first pregnancy, $98(30 \%)$ in the second pregnancy, $66(20 \%)$ in the third pregnancy, 28 patients $(8 \%)$ in the fourth pregnancy, and $10(2 \%)$ in the fifth pregnancy. Regarding employment status of the pregnant women, $28(5.6 \%)$ were employed and 302 were housewives (94.4\%). Regarding their respective husbands' employment, 57 participants $(14.7 \%)$ were employees, 25 (7.8\%) were unemployed, and $248(77.5 \%)$ were self-employed. Table 1 shows the demographic variables of the population under study. The results of a linear regression model showed that predicative variables of perceived susceptibility $(\beta=-0.05$ and $p>0.05)$, perceived severity $(\beta=0.63$ and $p>0.05)$ did not show predictive power, whereas response efficacy $(\beta=0.15$ and $p<0.05)$, and self-efficacy $(\beta=0.41$ and $p$ $<0.05$ ) showed significant relationships with self-care behavior against air pollution among pregnant women (Table 2). Spearman test results showed that there was a positive and significant correlation between self-care behavior against air pollution with perceived intensity structures $(r=0.18$ and $p<0.01)$, response efficiency $(r=0.329$ and $p$ $<0.01)$, and self-efficacy $(\mathrm{r}=0.263$ and $\mathrm{p}<0.01)$ (Table 3$)$. But there was no statistically significant relationship between the self-care and perceived susceptibility $(r=-0.035$ and $p>0.05)$. 
http://www.ephysician.ir

Table 1. Frequency of demographic variables in the population of study

\begin{tabular}{|c|c|c|c|}
\hline \multicolumn{2}{|l|}{ Variables } & $\mathrm{n}$ & $\%$ \\
\hline \multirow[t]{5}{*}{ Age (year) } & $19-15$ & 13 & 4 \\
\hline & $24-20$ & 56 & 17 \\
\hline & $29-25$ & 167 & 50.6 \\
\hline & $35-30$ & 77 & 23.3 \\
\hline & $>35$ & 17 & 5.1 \\
\hline \multirow[t]{3}{*}{ Trimester of pregnancy } & First trimester & 87 & 26.3 \\
\hline & Second trimester & 150 & 45.5 \\
\hline & Third trimester & 93 & 28.2 \\
\hline \multirow[t]{5}{*}{ Pregnancy order } & First pregnancy & 128 & 40 \\
\hline & Second pregnancy & 98 & 30 \\
\hline & Third pregnancy & 66 & 20 \\
\hline & Forth pregnancy & 28 & 8 \\
\hline & Fifth pregnancy & 10 & 2 \\
\hline \multirow[t]{2}{*}{ Employment status of pregnant women } & Employed & 28 & 5.6 \\
\hline & housewife & 302 & 94.4 \\
\hline \multirow[t]{3}{*}{ Employment status of pregnant women husbands } & Employed & 57 & 14.7 \\
\hline & Unemployed & 25 & 7.8 \\
\hline & Self-employment & 248 & 77.5 \\
\hline
\end{tabular}

Table 2. Regression coefficients of EPPM constructs against self-care behavior

\begin{tabular}{|l|l|l|l|l|}
\hline Variable & Regression coefficients & SD & t-statistics & p-value \\
\hline Susceptibility & -0.05 & 0.037 & -1.442 & 0.151 \\
\hline Severity & 0.63 & 0.689 & 0.924 & 0.357 \\
\hline Response efficacy & 0.15 & 0.051 & 3.088 & 0.002 \\
\hline Self-efficacy & 0.41 & 0.112 & 3.726 & 0.000 \\
\hline
\end{tabular}

Table 3. Matrix of Spearman's Correlation Coefficient among Extended Parallel Process Models

\begin{tabular}{|l|l|l|l|l|l|}
\hline Structures & Susceptibility & Severity & Response efficacy & Self-efficacy & Behavior \\
\hline susceptibility & 1 & & & & \\
\hline Severity & 0.295 & 1 & & & \\
\hline Response efficacy & 0.117 & 0.426 & 1 & & \\
\hline Self-efficacy & 0.2 & 0.075 & 0.275 & 1 & \\
\hline Behavior & -0.035 & 0.18 & 0.329 & 0.263 & 1 \\
\hline
\end{tabular}

\section{Discussion}

Previous interventions to reduce air pollution risk factors were not considered to be determinants of one's health behavior. In this study, behavioral factors as effective predictors of pregnant women's self-care behavior, to prevent complications of air pollution were examined, based on EPPM in order to design, evaluate, and perform more effective educational interventions. The results of this study showed that self-efficacy is a more accurate predictor of self-care behavior which is consistent with the result of previous research in this field (1). Constructs of perceived susceptibility and severity were not significant predictors of self-care behavior in the regression model. One of the reasons of inability of these constructs to predict self-care behavior might be due to the high scores of structures in the study population. This might be due to some health campaigns provided through public media such as TV and radio. In other words, the increased sensitivity about a health issue, cannot merely lead to adopt healthy behavior. This result is not consistent with the results of Dehghani Tafti et al. regarding diabetes self-care behavior. The reason for this inconsistency can be the difference in the type of investigated behavior; because in this study, selfcare behavior against air pollution while in the study of Dehghani et al. self-care behavior against diabetes had been investigated (23). Another finding of this study is a significant and positive linear correlation between the behavior and perceived severity, response efficacy, and self-efficacy. Studies have shown that self-efficacy, regardless of high perceived severity, can have a significant predictive role in health and self-care behavior (24). Although other research findings showed that response efficacy (25) and perceived susceptibility (26) have more predictive power 
in self-care behavior, in another study results showed self-efficacy as the most important factor in postnatal self-care behavior (physical activity and eating habits) in diabetic women (27). A study showed self-efficacy as an important factor in participation of women in the use of condoms (28). In addition to adopt a behavior, self-efficacy has also been reported as an important factor in determining intention of healthy behavior (29). Other findings of the study include lack of linear correlation between self-care and perceived susceptibility and severity. Findings of the present study are inconsistent with the findings of Sadeghi and et al.'s study about the low correlation between perceived severity and perceived susceptibility on behavior (30). Studies showed that the feeling of self-efficacy is a high level cognitive process that effects on how to solve the problem by ones in adopting health behavior $(31,32)$ this phenomenon might justify the low level correlations between self-care behavior and perceived susceptibility and severity. With regards to the limitations of the study, it can be said that the lack of sampling in rural areas of Ahvaz's West Health Center and low level of pregnant women's education in some areas were the limitations of this study.

\section{Conclusions}

In summary, the findings showed that self-efficacy and response efficacy are important factors to predict air pollution self-care behavior. Therefore, to develop a theory-based behavioral modification program for pregnant women, more emphasis on these constructs is recommended. The result of the present study can be a positive step towards the promotion of pregnant women's health with regards to air pollution condition in Ahvaz. Carrying out a complementary study on the impact of educational interventions designed on air pollution using EPPM structures on pregnant women and other vulnerable groups, such as patients of respiratory disease, heart disease, and the elderly is needed. Additionally applying rigorous methodologies such as Structural Equation Modeling (SEM) might be an appropriate way for future research on this topic.

\section{Acknowledgments:}

This paper is the result of a Master's thesis on health education, approved by the Social Determinants of Health Research Center, Ahvaz Jundishapur University of Medical Science with the number SDH9413. The authors are willing to acknowledge the pregnant women and also the cooperation and collaboration of workers at West Family Health Center of Ahvaz, especially Ms. Akbari (expert in mothers' program) and Ms. Khani (responsible for health education) cooperating with the investigation group.

\section{Conflict of Interest:}

There is no conflict of interest to be declared.

Authors' contributions:

All authors contributed to this project and article equally. All authors read and approved the final manuscript.

\section{References:}

1) Araban M, Tavafian SS, Motesaddi Zarandi S, Hidarnia AR, Gohari MR, Prochaska JM. Introducing a new measure for assessing self-efficacy in response to air pollution hazards for pregnant women. J Environ Health Sci Eng. 2013; 11(1): 16. doi: 10.1186/2052-336X-11-16. PMID: 24491221, PMCID: PMC3776291.

2) Mannucci PM, Harari S, Martinelli I, Franchini M. Effect on health of air pollution: a narrative review. Intern Emerg Med. 2015; 10(6); 657-62. doi: 10.1007/s11739-015-1276-7. PMID: 26134027.

3) Jonathan W. The air pollution capital of the world. The Lancet. 2005; 366: 1761-2. doi: 10.1016/S01406736(05)67711-2.

4) Santus P, Russo A, Madonini E, Allegra L, Blasi F, Centanni S, et al. How air pollution influences clinical management of respiratory diseases. A case-crossover study in Milan. Respir Res. 2012; 13: 95. doi: 10.1186/1465-9921-13-95. PMID: 23078274, PMCID: PMC3511062.

5) To T, Shen S, Atenafu EG, Guan J, McLimont S, Stocks B. The Air Quality Health Index and Asthma Morbidity: A Population-Based Study. Environ Health Perspect. 2012; 121(1): 46-52. PMID: 23060364, PMCID: PMC3546347.

6) Kashima S, Yorifuji T, Tsuda T, Eboshida A. Asian dust and daily all-cause or cause-specific mortality in western Japan. Occup Environ Med. 2012; 69(12): 908-15. doi: 10.1136/oemed-2012-100797. PMID: 23085558.

7) Shahsavani A, Naddafi K, Jafarzade Haghighifard N, Mesdaghinia A, Yunesian M, Nabizadeh R, et al. The evaluation of PM10, PM2.5 and PM1 concentration during the Middle Eastern Dust (MED) events in 
Ahvaz, Iran, from april through september 2010. Journal of Arid Environments. 2012; 77: 72-83. doi: 10.1016/j.jaridenv.2011.09.007.

8) Sekhavatjou MS, Alhashem AH, Taghavirad SS, Goudarzi G, Mollaee A. Seasonal variation of mercury vapour concentrations in industrial, residential, and traffic areas of Ahvaz city, Southwest Iran. African Journal of Biotechnology. 2011; 10(57): 12232-6. doi: 10.5897/AJB11.2033.

9) Khodarahmi F, Goudarzi G, Hashemi Shraki A, Bakhteyarvand N, Ahmadi Angali K, Dehghani M. Study of enviromental parameters effect on particulate matters and bacterial concerntration in Ahvaz city during different seasons. Ncmbj. 2013; 3(11): 83-90.

10) Modiri M, Ziaei S, Kazemnejad A. The effect of environmental carbon monoxide pollution on spontaneous abortion of the first trimester of pregnancy in tehran. Mjtuoms. 2012; 34(3): 106-1.

11) Taghdisi $M$, Nejadsadeghi $E$. The effect of health education based on health belief model on behavioural promotion of urinary infection prevention in pregnant women. Journal of Research \& Health. 2012; 2(1): 44-54.

12) Kariman N, Araban M, Motesaddi Zarandi S, Alavimajd H, Ahmadi M. Relationship emissions of sulfur dioxide in the air with low birth weight neonates in pregnant women admitted to hospitals in Tehran. Journal of Nursing \& Midwifery Faculty. 2008; 18(60): 22-8.

13) Araban M, Tavafian SS, Motesaddi Zarandi S, Hidarnia A, Gohari M, Laluei A, et al. Air pollution prevantive behavior among pregnant women: a theory based study. Journal of the iranian institue for health science research. 2013; 12(4): 385-91.

14) Dixon JK, Hendrickson KC, Ercolano E, Quackenbush R, Dixon JP. The environmental health engagement profile: what people think and do about environmental health. Public Health Nurs. 2009; 26(5): 460-73. doi: 10.1111/j.1525-1446.2009.00804.x. PMID: 19706129.

15) Giles LV, Barn P, Künzli N, Romieu I, Mittleman MA, van Eeden S, et al. From Good Intentional to Proven Intrrventions: Effectivness of Actions to Reduce Health Impacts of air pollution. Environ Health Perspect. 2011; 119(1): 29-36. doi: 10.1289/ehp.1002246. PMID: 20729178, PMCID: PMC3018496.

16) Rollnic S, Miller WR, Butler CC, Aloiab MS. Motivational Interviewing in Health Care: Helping Patients Change Behavior. Journal of Chronic Obstructive Pulmonary Disease. 2008; 5(3): 203. doi: 10.1080/15412550802093108.

17) JB. Principles of Health Education and Promotion. 3ed Wads Worth: USA. 2001; 235.

18) sharify $n$, kiasalar m, dinialy m. Family Self-Care Guide 1 . tehran: parsaysalamat. 2015; 6.

19) KW. Fear as motivator, Fear as inhibitor: using the extended parallel process model to explain fear appeal successes and failures, In: Andersen PA, Guerrero LK (eds). The Handbook of communication and emotion. Academic Press. 1998; 423-50.

20) Witte K. Putting the fear into fear appeals: The extended parallel process model. Commun Monogr. 1992; 59(4): 329-49. doi: 10.1080/03637759209376276.

21) Kleinbaum DG, Kupper LL, Muller KE. Applied regression analysis and other multivariable methods: PWS publishing. 1988; 718.

22) Yaghmale F. Content validity and its estimation. Journal of Medical Education. 2009; 3(1): 25-7.

23) Dehghani-Tafti A, Mazloomy Mahmoodabad SS, Morowatisharifabad MA, Afkhami Ardakani M, Rezaeipandari H1, Lotfi MH. Determinants of Self-Care in Diabetic Patients Based on Health Belief Model. Glob J Health Sci. 2015; 7(5): 33-42. PMID: 26156902, PMCID: PMC4803867.

24) Errett NA, Barnett DJ, Thompson CB, Tosatto R, Austin B, Schaffzin S, et al. Assessment of medical reserve corps volunteers'emergency response willingness using a threat- and efficacy-based model. Biosecur Bioterror. 2013; 11(1): 29-40. doi:10.1089/bsp.2012.0047. PMID: 23477632, PMCID: PMC3612278.

25) Ooms J, Jansen C, Hoeks J. The EPPM put to the test. Dutch Journal of Applied Linguistics. 2015; 4(2): 241-256. doi: 10.1075/dujal.4.2.07oom.

26) Gharlipour Z, Hazavehei SM, Moeini B, Nazari M, Beigi AM, Tavassoli E, et al . The effect of preventive educational program in cigarette smoking: Exended Parallel Process Model. J Educ Health Promot. 2015; 4: 4. doi: 10.4103/2277-9531.151875. PMID: 25767815, PMCID: PMC4355839.

27) Kaiser B, Razurel C, Jeannot E. Impact of health beliefs, social support and self-efficacy on physical activity and dietary habits during the post-partum period after gestational diabetes mellitus: study protocol. BMC Pregnancy childbirth. 2013; 13: 133. doi: 10.1186/1471-2393-13-133. PMID: 23800121, PMCID: PMC3694518. 
28) Nesoff ED, Dunkle K, Lang D. The Impact of Condom Use Negotiation Self-Efficacy and Partnership Patterns on Consistent Condom Use Among College-Educated Women. Health educ behave. 2016; 43(1): 61-7. doi:10.1177/1090198115596168. PMID: 26194206.

29) Huang HT, Kuo YM, Wang SR, Wang CF, Tsai CH. Structural Factors Affecting Health Examination Behavioral Intention. Int J Environ Res Public Health. 2016; 13(4): 395. doi: 10.3390/ijerph13040395. PMID: 27043606, PMCID: PMC4847057.

30) Sadeghi Sedeh B, Rabiei Z, Razavi H. Effects of health belief model components in general phjsicion rational prescribing of Chaharmahal va Bakhtiary provience. Razi Journal of Medical Sciences. 2015; 21(128): 37-47.

31) Wenze A, Beck At. A cognitive model of suicidal behavior: Theory and treatment. Appl prev psychol. 2008; 12(4): 189-201. doi: 10.1016/j.appsy.2008.05.001.

32) Zamani-Alavije F, Shahry P, Kalhori M, Araban M. Pregnant women's preferences for mode of delivery questionnaire: Psychometric properties. Journal of Education and Health Promotion. 